\title{
Desprendimiento androcéntrico. Pensar la matriz colonial de poder desde los aportes de Silvia Federici y Maria Lugones ${ }^{1}$
}

\footnotetext{
Luciano Fabbri ${ }^{2}$

Instituto Interdisciplinario de Estudios de Género, Buenos Aires, Argentina $^{3}$

lucho_fabbri@yahoo.com.ar

Recibido: 15 de septiembre 2013

Aceptado: 23 de enero de 2014

Artículo de reflexión que presenta los resultados del trabajo de investigación realizado para el Seminario de Postgrado "Teoría del Estado en América Latina", dictado por el Dr. Emilio Taddei, en el marco del Doctorado en Ciencias Sociales de la Universidad de Buenos Aires. El autor realiza su investigación doctoral "De la política antipatriarcal a la despatriarcalización. Narrativas de mujeres feministas de la izquierda independiente Argentina”, becado por la Comisión Nacional de Investigaciones Científicas y Tecnológicas.

2 Licenciado en Ciencia Política de la Universidad Nacional de Rosario. Doctorando en Ciencias Sociales de la Universidad de Buenos Aires. Becario CONICET.

3 Investigador. Integrante del Núcleo Interdisciplinario de Estudios y Extensión en Género (UNR) y del Centro de Estudios para el Cambio Social.

Documento accesible en línea desde la siguiente dirección: http://revistas.javeriana.edu.co
}

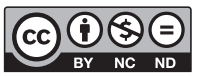




\section{Desprendimiento androcéntrico. Pensar la matriz colonial de poder desde los aportes de Silvia Federici y Maria Lugones}

\section{Resumen}

Este artículo pretende aportar a la comprensión del carácter sexuado generizado y racializado de la colonialidad, desde una aproximación crítica a la noción de matriz colonial de poder. Recuperando las contribuciones feministas de Federici y Lugones, complejizaremos el lugar que el género, la sexualidad y la raza tienen en la configuración del sistema de dominación. En el caso de Federici, procuraremos recuperar el rol que le asigna a la caza de brujas en el proceso de acumulación primitiva del capital, ampliando y complejizando esta noción clave de la teoría marxista. En el caso de Lugones, apelamos a su crítica a Quijano, para estirar los límites de la compresión en torno al lugar del género y la sexualidad en la configuración de la matriz colonial de poder. Retomando el vuelco descolonial como perspectiva crítica al marxismo eurocéntrico, buscaremos contribuir desde el feminismo, al desprendimiento androcéntrico de la perspectiva descolonial.

Palabras clave: desprendimiento androcéntrico; matriz colonial de poder; Federici; Lugones

\section{Androcentric Detachment. Thinking the colonial matrix of power from the contributions of Silvia Federici and Maria Lugones}

\section{Resumen}

This article seeks to contribute to the understanding of the gendered and racialized nature of colonialism from a critical approach of the notion of colonial matrix of power. Bringing back Federici's and Lugones' feminist contributions, we will deepen the place that gender, sexuality and race have in shaping the system of domination. In the case of Federici, we will try to recover the role assigned to the witch hunts in the process of primitive accumulation of capital, expanding and deepening this key notion of the Marxist theory. In the case of Lugones, we appeal to her critique of Quijano to stretch the compression limits around the place of gender and sexuality in shaping the colonial matrix of power. Picking up again the decolonial upset as a critical approach to Eurocentric Marxism, we seek to contribute, from feminism, to the androcentric detachment of the decolonial perspective. Keywords: androcentric detachment; colonial matrix of power; Federici; Lugones

\section{Desprendimento androcéntrico. Pensar a matriz colonial de poder desde os aportes de Silvia Federici e Maria Lugones}

\section{Resumo}

Este artigo visa aportar à compreensão do carácter sexuado generizado e racializado da colonialidade, desde uma aproximação crítica à noção de matriz colonial de poder. Recuperando as contribuições feministas de Federici e Lugones, complexaremos o lugar que gênero, sexualidade e raça têm na configuração do sistema de dominação. No caso de Federici, procuraremos recuperar o papel que assigna à caça às bruxas no processo de acumulação primitiva de capital, estendendo e complexando esta noção chave da teoria marxista. No caso de Lugones, apelamos a sua crítica a Quijano, para alongar os limites da compreensão em torno do lugar do gênero e a sexualidade na configuração da matriz colonial de poder. Retomando o giro descolonial como perspectiva crítica ao marxismo eurocêntrico, visaremos contribuir desde o feminismo, ao desprendimento androcêntrico da perspectiva descolonial. Palavras-chave: desprendimento androcêntrico; matriz colonial de poder; Federicç; Lugones 


\section{Introducción}

En las teorizaciones en torno a la colonialidad del poder y la matriz colonial de poder podemos encontrar una problemática común en torno a las limitaciones para comprender el lugar que el género y la sexualidad tienen en la configuración de las modalidades de dominación, permeando las relaciones de clase y raza que aparecen reiteradamente como principal (y a veces exclusivo) objeto de análisis. De igual manera, cuando el género es efectivamente incorporado como categoría de análisis relevante -como sucede en el análisis de Quijano-, el vuelco descolonial en tanto operación epistémica, no cuenta con la misma suerte que en el análisis de la categoría de raza, siendo limitado el alcance de la desnaturalización de las esferas que lo constituyen y por ende, reproduciéndose algunas características centrales de su configuración como política de dominación colonial.

En ese sentido, propongo aportar a la comprensión de la interseccionalidad clase, raza, género, sexualidad en la configuración de la matriz colonial de poder, proponiendo para ello una tarea epistemológica denominada desprendimiento androcéntrico. Con este objetivo, el artículo se centra en las contribuciones de las producciones feministas de Silvia Federici y María Lugones, que retomando nociones claves desarrolladas por Karl Marx y Aníbal Quijano respectivamente, complejizan el lugar que tienen el género y la sexualidad en la configuración del sistema de dominación.

En el caso de Silvia Federici, me propongo recuperar el rol que esta feminista italiana le asigna a la caza de brujas, tanto en la Europa feudal como en la América colonial, en el proceso de acumulación primitiva del capital, ampliando y complejizando esta noción clave de la teoría marxista. En el caso de María Lugones, me interesa retomar su recuperación crítica de la colonialidad del poder de Aníbal Quijano, estirando los límites de su compresión en torno al lugar del género y la sexualidad en la configuración de la matriz colonial de poder.

De esta forma, busco aportar y visibilizar el carácter generizado y racializado del proceso de construcción del patrón colonial de poder, ubicando solo algunos de los aportes sustanciales que la perspectiva feminista puede realizar a la perspectiva geopolítica y corpo-politica del conocimiento elaborada por Walter Mignolo. 


\section{Desprendimiento epistemológico, descolonialidad y género.}

En su libro Desobediencia epistémica: retórica de la modernidad, lógica de la colonialidad, gramática de la descolonialidad, Walter Mignolo plantea una pregunta que resulta de especial interés para los objetivos de estas reflexiones: “¿qué transformaciones son necesarias en la teoría crítica si el género, la raza y la naturaleza se incorporan plenamente en el marco conceptual y político?" (2010, p. 8).

A partir de este interrogante, Mignolo desarrolla la noción de desprendimiento epistemológico, estrechamente ligada a la perspectiva decolonial. Mignolo plantea que es en la década de 1970 cuando se comienza a debatir la ligazón entre el conocimiento y la colonización y como consecuencia, la necesidad de descolonizar el conocimiento para desarrollar cualquier proceso de descolonización política y económica. A su vez, reconoce en la producción del sociólogo peruano Aníbal Quijano, y su conceptualización sobre la colonialidad de poder, una herramienta teórica que estira los limites de la comprensión alcanzada hasta ese entonces. Esta conceptualización permite ver el lazo entre la colonización política y económica y la colonialidad del saber y del ser, postulando que la matriz colonial del poder es una estructura compleja de niveles entrelazados que incluye el control de la economía, el control de la autoridad, el control de la naturaleza y de los recursos naturales, el control del género y la sexualidad, y el control de la subjetividad y el conocimiento (Quijano, 2000; Mignolo, 2010).

Puntualmente, Quijano plantea cuatro esferas entrelazadas en la configuración de la matriz colonial de poder:

1. La privatización y explotación de la tierra y la explotación de la mano de obra.

2. El control de la autoridad (virreinatos, estados coloniales, estructura militar).

3. El control del género y la sexualidad (la familia cristiana, valores y conductas sexuales y de género).

4. El control de la subjetividad (la fe cristiana, la idea secular de sujeto y ciudadano) y el conocimiento (principios de teología, filosofia secular, concepto de razón, derecho y medicina).

Es a partir de los aportes de Edgardo Lander y Vandana Shiva que Mignolo incorpora las esferas del control de la naturaleza y los recursos naturales, originalmente contenidas en el punto 1. 
Para el autor, estas cinco esferas de la experiencia humana están interrelacionadas a través del conocimiento (la justificación racional del orden del mundo), de la enunciación (el racismo y el patriarcado que subyace a la clase etnia) y a la composición genérica y preferencias sexuales de la élite que fundó y mantuvo cierto orden del mundo mediante el control del conocimiento (Mignolo, 2010).

Ahora bien, según Mignolo, las reflexiones de Quijano contienen dos momentos; un primer momento analítico, caracterizado por la crítica de la noción moderna de totalidad y un segundo momento programático, presentado como proyecto de desprendimiento o de-linking. Es este segundo momento el que constituye principalmente el distanciamiento de la perspectiva descolonial con respecto a la crítica postcolonial, subsumiendo la segunda en la primera. De esta manera,

El vuelco descolonial es un proyecto de desprendimiento epistémico en la esfera de lo social (también en el ámbito académico, por cierto, que es una dimensión de lo social), mientras que la crítica post-colonial y la teoría crítica son proyectos de transformación que operan y operaron básicamente en la academia europea y estadounidense" (Mignolo, 2010, p. 15).

Los esquemas de pensamiento originados en Occidente, incluso aquellos caracterizados como emancipatorios, se mantendrian dentro de los límites de las políticas imperiales del conocimiento y el entendimiento, denominadas teopolitica y egopolitica del conocimiento. La segunda sería propia de la racionalidad moderna, emergente del proceso de secularización del Estado (y del conocimiento) a partir del Renacimiento y la Ilustración.

La perspectiva superadora, enmarcada en el vuelco descolonial, estaria dada por la emergencia de una geopolítica y corpo-politica del conocimiento. Mientras la geopolitica:

[...] nombra la ubicación histórica (espacio y tiempo, los referentes históricos y la configuración del tiempo y el espacio, etc.) y la autoridad de la localización de las enunciaciones negadas y devaluadas por parte de la dominación y la hegemonía de ambas políticas imperiales del conocimiento y del entendimiento [...] la corpo-política, "es más apropiada para hacer visible el color, el género y la sexualidad del "cuerpo pensante", visibilizando asî la corpo-política blanca, masculina y heterosexual que reposa, invisible, detrás de las 
políticas hegemónicas del conocimiento en la modernidad imperial europea" (2010, pp. 37-41).

Ahora bien, una vez explicitadas las características de este vuelco descolonial, o desprendimiento epistemológico, la multiplicidad de esferas de la experiencia humana que constituyen los ámbitos del control ejercido por la matriz colonial de poder son básicamente reducidos a la clasificación de la población, en función de la fe y la complexión física, ligadas a la invención de la raza como criterio de diferenciación y jerarquización entre las poblaciones. De forma tal que Mignolo expresa que "el racismo y la colonialidad del ser son una y la misma operación cognitiva arraigada en el plano filosófico en la matriz colonial de poder" (Mignolo, 2010, p. 84).

De esta manera, el lugar del género y la sexualidad como criterio de clasificación poblacional y elemento constitutivo de la matriz colonial de poder, queda subsumido en la esfera de la racialización, al punto de que por momentos su problematización se ve reducida a la enunciación del problema de la enunciación.

Identificada esta limitación, podría afirmar que la corpo-politica del conocimiento considerada en el vuelco descolonial, si bien logra jaquear el carácter occidentalista y etnocéntrico de las politicas de entendimiento imperial, no lo logra actuar de la misma manera con respecto al carácter androcéntrico de las mismas, repitiendo la operación a través de la cual el cuerpo del conocimiento, esta vez un cuerpo geopolíticamente ubicado en la exterioridad de la blanquitud hegemónica, continúa siendo implícitamente, un cuerpo masculino y heterosexual.

La reflexión sobre los cuerpos desde los cuales se produce conocimiento y el carácter generizado y sexualizado de los mismos, tiene un vasto recorrido dentro de la teoría feminista. En la misma medida, nos encontramos con una descolonización de las reflexiones emergentes de las feministas blancas por parte de un feminismo descolonial, de color, fronterizo, que entrecruzará dicha reflexión en torno al cuerpo sexuado con las políticas de racialización y colonización epistémica. De esta manera, quisiera recuperar los aportes de Silvia Federici y María Lugones, en tanto encuentro en sus reflexiones, elementos que aportarian al necesario desprendimiento androcéntrico en la perspectiva descolonial. 


\section{Las mujeres como bienes comunes: Nuevo orden patriarcal y acumulación primitiva}

En Calibán y la bruja. Mujeres, cuerpo y acumulación originaria (2011), la feminista italiana Silvia Federici, analiza el proceso de transición ${ }^{4}$ del feudalismo al capitalismo desde un punto de vista feminista, poniendo en el centro de la reflexión el deterioro que significó para la posición social de las mujeres en particular, pero también para la ruptura de las solidaridades comunales en el marco de las resistencias a las transformaciones estructurales regresivas.

Si bien la mayor parte de su producción está contextualizada en las luchas anti-feudales y resistencias a la implantación de las relaciones de clase capitalistas en Europa, podemos encontrar también una serie de elementos que nos permiten complejizar la caracterización de la configuración de la matriz colonial de poder en el Nuevo Mundo, especialmente en lo que respecta al género y la sexualidad en su intersección con la clase y la raza.

Un eje de interés para nuestras reflexiones, y central en el desarrollo de sus postulados, es la crítica a la noción de acumulación originaria (o primitiva, dependiendo de la traducción) en Marx. Encontramos en esta crítica un estimable aporte al desprendimiento androcéntrico, no solo de la teoría marxista, sino del pensamiento crítico en general, incluyendo la perspectiva descolonial en este universo.

En palabras de la autora:

Si Marx examina la acumulación originaria desde el punto de vista del proletariado asalariado de sexo masculino y el desarrollo de la producción de mercancías, yo la examino desde el punto de vista de los cambios que introduce en la posición social de las mujeres y en la reproducción de la fuerza de trabajo. Estas dos realidades están estrechamente conectadas en éste análisis, ya que en el capitalismo la reproducción generacional de los trabajadores y la generación cotidiana de su capacidad de trabajo se han convertido en "trabajo de mujeres", si bien mistificado, por su condición no asalariada, como servicio personal e incluso como recurso natural. (Federici, 2011, p. 23)

Las cursivas en transición aluden a la crítica que la autora hace de este concepto por sugerir un proceso gradual, lineal y continuo, nombrando uno de los procesos más sangrientos y discontinuos de la historia. 
Es en este sentido que la autora se propone demostrar que la caza de brujas (al igual que la trata de esclavos, los cercamientos de las tierras del campesinado europeo y de las tierras comunales de los pueblos colonizados de América) constituyó un aspecto central de la acumulación y formación del proletariado moderno, tanto en Europa como en el Nuevo Mundo.

La caza de brujas, también entendida como una guerra contra las mujeres, es contextualizada por Federici entre los esfuerzos principales de las clases dominantes por vencer las luchas anti-feudales del campesinado europeo contra la servidumbre; las luchas de los movimientos heréticos contra las autoridades clericales y seculares, levantando un programa de renovación espiritual y justicia social; las resistencias a la instalación de relaciones capitalistas basadas en la expropiación de las tierras comunales y la salarización del trabajo con una fuerte participación femenina en todos los casos-, y los cada vez más intensos esfuerzos estatales por controlar la esfera de la reproducción, en la cual la sexualidad y los cuerpos de las mujeres aparecian con un inédito interés.

Según Federici, ya en los códigos sexuales y reproductivos de los herejes podemos hallar las huellas de un intento de control medieval de la natalidad, lo cual explicaría el motivo por el cual, cuando el crecimiento poblacional se convirtió en una preocupación social fundamental durante la profunda crisis demográfica (reducción poblacional en 30 a 40\%) y la escasez de trabajadores a finales del siglo XIV (Gran hambruna (1315-1322) y Peste Negra (1347-1352), la herejía comenzó a ser asociada a los crimenes reproductivos, especialmente la sodomía, el infanticidio y el aborto.

Coincidiendo con este proceso que marcó la transición de la persecución de la herejía a la caza de brujas, la mujer se convirtió de forma cada vez más clara en la figura de lo hereje, de tal manera que hacia comienzos del siglo XV, la bruja se transformó en el principal objetivo en la persecución de los herejes. A su vez, es de fundamental importancia aclarar que en la persecución a las brujas se condensaba un objetivo mucho más amplio: la demonización de la feminidad y el disciplinamiento y domesticación de las mujeres en general.

La escasez de mano de obra produjo una alteración sustancial de las relaciones de poder, fortaleciendo la posición de las clases bajas que comenzaron a negarse a pagar multas y rentas, brindar servicios laborales, entre otros instrumentos claves del poder feudal. Para finales del siglo XV y con la finalidad de recuperar las posiciones de poder 
perdidas, se puso en marcha una contrarrevolución que actuaba en todos los niveles de la vida social y politica. Es en este contexto que ganaron posición las posturas mercantilistas de que la cantidad de ciudadanos determina la riqueza de una nación, sintetizando el pensamiento demográfico de la época y constituyendo las bases de una política reproductiva capitalista, expresada en las medidas pro-natalistas impulsadas desde el Estado:

- Jerarquización de la familia como institución clave para asegurar la transmisión de la propiedad y la reproducción de la fuerza de trabajo.

- La devaluación del trabajo femenino reduciendo a las mujeres a no-trabajadores, a través de su exclusión de aquellas ocupaciones que habian sido prerrogativas suyas, la prohibición estatal de su representación y protección gremial, la desposesión de la tierra, la masificación y posterior criminalización de la prostitución (tiempo atrás promovida desde el Estado), la aparición de la ama de casa y redefinición de la familia como lugar de producción de la fuerza de trabajo.

- Intervención del Estado en la supervisión de la sexualidad, la procreación y la familia, combinando el comienzo del registro demográfico, el surgimiento de las políticas de asistencia social, el agravamiento de las penas por anticoncepción, aborto e infanticidio, y el quiebre del control de las mujeres sobre sus cuerpos y su reproducción a través de la demonización de toda forma de control de la natalidad y de la sexualidad no procreativa, librada principalmente a través de la caza de brujas.

Retomando una de las hipótesis centrales de la obra de Federici,

[...] si consideramos el contexto social en el que se produjo la caza de brujas, el género y la clase de las acusadas y los efectos de la persecución, podemos concluir que la caza de brujas en Europa fue un ataque a la resistencia que las mujeres opusieron a la difusión de las relaciones capitalistas y al poder que habian obtenido en función de su sexualidad, su control sobre la reproducción y su capacidad de curar. La caza de brujas fue también instrumental a la construcción de un orden patriarcal en el que los cuerpos de las mujeres, su trabajo, sus poderes sexuales y reproductivos fueron colocados bajo el control del Estado y transformados en recursos económicos. (Federici, 2011, pp. 232-233) 
Retomando los aportes de la politóloga australiana Carole Pateman (1988), Federici conceptualiza este reordenamiento social como un contrato sexual, mediante el que las mujeres (que no habian sido privatizadas por los hombres burgueses) constituirian para los trabajadores, el sustituto de las tierras que habian perdido por los cercamientos, convirtiéndose en un bien común,

[...] pues una vez que las actividades de las mujeres fueron definidas como no-trabajo, el trabajo femenino se convirtió en un recurso natural, disponible para todos, no menos que el aire que respiramos o el agua que bebemos. (Federici, 2011, p. 148)

Esto fue logrado a través de la constitución de un nuevo orden patriarcal o Patriarcado del salario; excluyendo a las mujeres del salario e imposibilitando así su independencia económica, se crearon las condiciones materiales para su sujeción a los hombres.

Una vez destruido, a través de la caza de brujas, el mundo de prácticas femeninas, relaciones colectivas y sistemas de conocimiento que habían sido la base del poder de las mujeres en la Europa precapitalista, la imagen de la feminidad como factor de peligro fue reemplazada por una domesticada: el modelo de feminidad de la mujer y esposa ideal.

Pero quizás más importante para la transición del feudalismo al capitalismo, sea el hecho de que:

[...] la caza de brujas ahondó las divisiones sociales entre mujeres y hombres, inculcó a los hombres el miedo al poder de las mujeres y destruyó un universo de prácticas, creencias y sujetos sociales cuya existencia era incompatible con la disciplina del trabajo capitalista, redefiniendo así los principales elementos de la reproducción social. (Federici, 2011, p. 223)

A través de este análisis podemos encontrar algunos elementos para trascender la dicotomía entre género y clase, abordando al género,

[...] como una especificación de las relaciones de clase. Para decirlo de otra manera: en la sociedad capitalista la "feminidad" se ha constituido en una función trabajo que oculta la producción de la fuerza de trabajo bajo la cobertura de un destino biológico. (Federici, 2011, p. 27) 
Esta búsqueda por trascender la dicotomía entre género y clase, no será para la autora una mera herramienta analitica para el diagnóstico de las formas en que estas esferas se encuentran imbricadas en la construcción del tejido social, sino además, una clave fundamental para pensar la necesaria articulación entre luchas feministas y anticapitalistas. Atendiendo a que cuando hablamos de androcentrismo, no solo aludimos al sexismo, sino a su articulación con el racismo, el clasismo y el colonialismo (hombre blanco, heterosexual, burgués y occidental como centro). La propuesta teórica de Federici y la forma en que podemos recuperarla para un análisis crítico de la matriz colonial de poder, nos invita a pensar en el carácter necesariamente anticapitalista del vuelco feminista propuesto para la materialización del desprendimiento androcéntrico ${ }^{5}$.

El análisis del fenómeno de la caza de brujas, además de informarnos sobre la importancia del género y la sexualidad en la transformación de las relaciones de clase en Europa, resulta de especial interés para la caracterización del Capitalismo colonial moderno, en tanto fue una experiencia importada por la clases dominantes a la América colonial en sus politicas de control del trabajo, a través de la colonialidad del saber y del ser. Esto se ve reflejado cuando Federici plantea que los homólogos a las brujas europeas, fueron los indígenas americanos colonizados y los africanos esclavizados que compartieron un destino similar al de las mujeres en Europa,

[...] proveyendo al capital del aparentemente inagotable suministro de trabajo necesario para la acumulación. La "caza de brujas" y las acusaciones de adoración al Demonio fueron llevadas a América para quebrar la resistencia de las poblaciones locales, justificando así la colonización y la trata de esclavos ante los ojos de mundo" (Federici, 2011, pp. 272-273).

Este destino común entre las brujas europeas y los súbditos coloniales también queda en evidencia en la creciente retroalimentación

\footnotetext{
"El diferencial de poder entre mujeres y hombres en la sociedad capitalista [...] debía interpretarse como el efecto de un sistema de producción que no reconoce la producción y reproducción del trabajo como una actividad socio-económica y como una fuente de acumulación del capital y, en cambio, la mistifica como un recurso natural o un servicio personal, al tiempo que saca provecho de la condición no asalariada del trabajo involucrado. A raíz de la explotación de las mujeres en la sociedad capitalista, la división sexual del trabajo y el trabajo no pagado realizado por mujeres, Dalla Costa y James demostraron que era posible trascender la dicotomía entre el patriarcado y la clase, otorgando al patriarcado un contenido histórico específico. También abrieron el camino para una reinterpretación de la historia del capitalismo y de la lucha de clases desde un punto de vista feminista" (Federici, 2011, p. 13).
} 
entre la doctrina de la brujería y la ideología racista que se desarrolló en la América colonial. Un ejemplo propuesto por Federici es que el "Diablo era representado como un hombre negro, y los negros eran tratados cada vez más como diablos" (2011, p. 272).

Al igual que en el caso de la demonización de las mujeres europeas, el sello de lo diabólico era caracterizado como un deseo y una potencia sexual anormales. Según la autora,

[...] la sexualización exagerada de las mujeres y los negros -las brujas y los demonios- también debe estar enraizada con la posición que ocupaban en la división internacional del trabajo que surgió a partir de la colonización de América, la trata de esclavos y la caza de brujas. La definición de negritud y feminidad como marcas de bestialidad e irracionalidad se correspondía con la exclusión de las mujeres en Europa, así como de las mujeres y los hombres en las colonias, del contrato social implícito en el salario, con la consecuente naturalización de su explotación.- (Federici, 2011, p. 275)

Otros trabajos de investigación, como La luna, el sol y las brujas, de Irene Silverblatt (1987), Brujas y poder, de Luciano Parinetto (1998),

[...] demuestran que, también en el Nuevo Mundo, la caza de brujas constituyó una estrategia deliberada, utilizada por las autoridades con el objetivo de infundir terror, destruir la resistencia colectiva, silenciar a comunidades enteras y enfrentar a sus miembros entre sí. También fue una estrategia de cercamiento de tierra, de cuerpos o relaciones sociales. Al igual que en Europa, la caza de brujas fue, sobre todo, una estrategia de deshumanización y, como tal, la forma paradigmática de represión que servia para justificar la esclavitud y el genocidio. (Federici, 2011, p. 289)

Si bien la demonización de los súbditos coloniales pareciera estar principalmente justificada a partir de la racialización como mecanismo de inferiorización de la población, y por ende dirigida tanto hacia hombres como mujeres, aquí también cobra relevancia la generización y sexualización de las formas de dominación, con especial interés por la subordinación de las mujeres.

Si bien pueden observarse mecanismos de sujeción de las mujeres en las sociedades pre-colombinas, por ejemplo, en el Imperio 
Azteca, también es cierto que ellas conservaban posiciones de poder que fueron atacadas por los colonizadores. Una muestra de ellos es la existencia de muchas deidades femeninas de importancia en las religiones pre-colombinas, así como el reconocimiento de sus actividades sociales como complementarias -y no inferiores- a las desarrolladas por los hombres. Todo esto fue cambiando con la llegada de los colonizadores que "trajeron consigo su bagaje de creencias misóginas y reestructuraron la economia y el poder politico en favor de los hombres" (Federici, 2011, p. 305). Fueron expropiadas de sus tierras y de sus derechos sobre el agua, reducidas a la condición de siervas que trabajaban como sirvientas de encomenderos, sacerdotes y corregidores, y obligadas a seguir a sus maridos - para entre otras cosas, hacerse cargo de alimentarlos -cuando eran enviados a hacer el trabajo de mita en las minas.

Estos ataques misóginos explican el porqué

[...] las mujeres se convirtieron en las principales enemigas del dominio colonial, negándose a ir a misa, a bautizar a sus hijos o a cualquier tipo de colaboración con las autoridades coloniales y los sacerdotes, (también) el porqué las mujeres constituyeron la columna vertebral del movimiento Taki Ongoy ${ }^{6 "}$ (Federici, 2011, pp. 305306).

Los correlatos encontrados en los procesos europeos y coloniales, nos brindan dos aportes de relevancia. En primer lugar, aportan en el plano de la descolonialidad del saber, a "disipar el eurocentrismo que ha caracterizado al estudio de la caza de brujas" (2011,p. 310). En segunda instancia,

[...] amplía nuestra conciencia sobre el carácter global del desarrollo capitalista y ayuda a que nos demos cuenta de que, en el Siglo XVI, ya existía en Europa una clase dominante que estaba, desde todo punto de vista -en términos prácticos, políticos e ideológicos-, implicada en la formación de una mano de obra a nivel mundial y que, por lo tanto, actuaba continuamente a partir del conocimiento que recogía a nivel internacional para la elaboración de sus modelos de dominación. (Federici, 2011, p. 310)

6 Movimiento nativo milenarista nacido en Perú alrededor de 1560. Predicaba contra el colaboracionismo con los europeos y a favor de una alianza pan-andina de los dioses locales (huacas) para poner fin a la colonización. El nombre Taki Ongoy describe el trance en el que, durante el baile, entraban los participantes en el movimiento. 
Por todo lo expuesto es que la autora afirma que

La acumulación primitiva no fue, entonces, simplemente una acumulación y concentración de trabajadores explotables y capital. Fue también una acumulación de diferencias y divisiones dentro de la clase trabajadora, en la cual las jerarquías construidas a partir del género, así como las de "raza" y edad, se hicieron constitutivas de la dominación de clase y de la formación del proletariado moderno. (Federici, 2011, p. 90)

En función del objetivo planteado en este artículo, de contribuir al desprendimiento androcéntrico de la perspectiva descolonial a través de una mejor comprensión de la intersección entre clase, género y raza, en la configuración de la matriz colonial de poder, coincidimos con Federici en que

La lección que podemos aprender de Calibán y la bruja es que el capitalismo, en tanto sistema-económico social, está necesariamente vinculado con el racismo y el sexismo. El capitalismo debe justificar y mistificar las contradicciones incrustadas en sus relaciones sociales denigrando la "naturaleza" de aquellos a quienes explota: mujeres, súbditos coloniales, descendientes de esclavos africanos, inmigrantes desplazados por la globalización. (2011, p. 32)

\section{Interseccionalidad y colonialidad de género en el capitalismo colonial moderno}

Otro aporte relevante a los objetivos de este trabajo, es el realizado por la feminista María Lugones en su artículo "Colonialidad y Género" (2008), donde se propone abordar la interseccionalidad entre raza, clase, género y sexualidad,

[...] con el objetivo de entender la preocupante indiferencia que los hombres muestran hacia las violencias que sistemáticamente se infringen contra las mujeres de color, es decir, mujeres no blancas víctimas de la colonialidad del poder e, inseparablemente, de la colonialidad del género. (Lugones, 2008, p. 73) 
Lugones entiende esa indiferencia ante la violencia hacia las mujeres de sus mismas comunidades, como una indiferencia hacia transformaciones sociales profundas en las estructuras comunales y por lo tanto, totalmente relevantes al rechazo de la imposición colonial. Seguimos a esta autora cuando afirma que esta indiferencia también se expresa al nivel de teorizar la opresión y la liberación, motivo por el cual resulta de interés a los fines de contribuir al desprendimiento androcéntrico en tanto tarea politica epistémica.

A raíz de esta inquietud, se plantea la necesidad de relacionar dos marcos teóricos que no han sido suficientemente explorados de forma conjunta; el desarrollado por las feministas de color en EE.UU y el Tercer Mundo, haciendo énfasis en la noción de interseccionalidad y el trabajo teórico de Aníbal Quijano con relación a la colonialidad del poder.

Lugones encuentra que "la interseccionalidad revela lo que no se ve cuando categorias como género y raza se conceptualizan como separadas una de otra" (2008, p. 81). Esta invisibilidad se debería a que las categorias son entendidas como homogéneas y que selecciona al dominante en el grupo como su norma.

Lugones recupera la teorización de Quijano sobre la colonialidad del poder y la estructuración del mismo en torno a la disputa por el control de los cuatro ámbitos de la existencia humana: sexo, trabajo, autoridad colectiva y subjetividad/intersubjetividad, sus recursos y productos, para luego plantear que su análisis de la construcción moderna/colonial del género es limitado:

[...] la mirada de Quijano presupone una concepción patriarcal y heterosexual de las disputas por el control del sexo, y sus recursos y productos. Quijano acepta el entendimiento capitalista, eurocentrado y global del género [y] vela las maneras en que las mujeres colonizadas, no-blancas, fueron subordinadas y desprovistas de poder. (Lugones, 2008, p. 78)

Este velo en el patrón de Quijano no estaría dado por una separación entre género y raza (por lo contrario, Lugones considera correcta su formulación en este sentido), sino por la forma en que el género es conceptualizado en su modelo. O por el contrario, por la omisión de una conceptualización en torno al mismo, lo que lleva a entender que, aparentemente en el patrón de Quijano, el género parece estar contenido dentro de la organización de aquel ámbito básico de la existencia 
que el autor denomina sexo, sus recursos y productos. De esta manera, la noción de género no se coloca bajo interrogación.

Según la autora, para arribar a una comprensión de la organización diferencial del género en términos raciales, es imprescindible entender los rasgos históricamente específicos de la organización del género en el sistema moderno/colonial de género, a saber; el dimorfismo biológico (dicotomía varón/mujer) y la organización patriarcal y heterosexual de las relaciones sociales.

En relación al dimorfismo biológico, Lugones refuta que la división sexual esté basada en la biología. En esta clave aparece una de las críticas a Quijano, ya que, a diferencia de su conceptualización en torno al carácter ficticio de la raza, la noción de género expresada naturaliza las diferencias sexuales, reproduciendo los marcos conceptuales de la ciencia moderna en torno a la sexualidad y el género.

Así como Silvia Federici analiza los cambios en la posición social de las mujeres a partir de la transición del feudalismo al Capitalismo, Lugones analiza la subordinación de las hembras en todos los aspectos de la vida como resultante del sistema de género impuesto a través de la colonización. Apoyándose en la obra de la nigeriana Oyéronké Oyewúmi, La Invención de las Mujeres (1997), afirma que

[...] la emergencia de la mujer como una categoría reconocible, definida anatómicamente y subordinada al hombre en todo tipo de situación, resultó, en parte, de la imposición de un Estado colonial patriarcal. Para las mujeres, la colonización fue un proceso dual de inferiorización racial y subordinación de género. Uno de los primeros logros del Estado colonial fue la creación de las "mujeres" como categoría. (Oyewúmi (1997) citado en Lugones, (2008, p. 88))

Si bien en Federici la preocupación en torno a la construcción/ historización del género está más vinculada a su relación con la clase que con la raza, su análisis de la constitución de la feminidad (y de las mujeres como categoría de análisis), "como una función-trabajo que oculta la producción de la fuerza de trabajo bajo la cobertura de un destino biológico" (2011, p. 26), nos permite trazar un puente entre ambas autoras. Sea en el análisis de la acumulación capitalista primitiva en Federici, como en el del sistema moderno colonial de género en Lugones, encontramos una funcionalidad histórica en el surgimiento del género como variable de clasificación, jerarquización y división de 
la población al servicio de los poderes dominantes y en detrimento de las solidaridades y resistencias comunales.

Lugones a su vez, afirma que en la misma operación en que la mujer es construida e inferiorizada, los hombres colonizados serán cooptados por el colonizador blanco como forma de fragmentar las solidaridades comunales y construir fuerza interna hacia dentro de las tribus a partir de la complicidad masculina interracial e interclasista.

Al considerar que la colonialidad de género elaborada por Quijano no pone al descubierto el carácter ficticio del género y del sexo y el diferencial de poder resultante de dicha construcción relacional, Lugones afirma que el marco de Quijano "parece caer en cierta presuposición respecto a quién controla el acceso y quiénes son constituidos como recursos", lo que expresa según sus términos, una "concepción patriarcal" del género (Lugones, 2008, p. 85).

Así como Lugones nos presenta producciones que dan cuenta de la invención de la mujer, hace lo propio respecto a la heterosexualidad. Apela a estudios antropológicos que documentan la presencia de la sodomía y la homosexualidad masculina (y en menor grado femenina) en la América pre-colombina y colonial, como evidencia de que, "la heterosexualidad característica de la construcción colonial moderna de las relaciones de género es producida y construida míticamente". Agregando que,

[...] la heterosexualidad no está simplemente biologizada de una manera ficticia, [sino que] también es obligatoria y permea la totalidad de la colonialidad del género [...] que esta heterosexualidad ha sido coherente y duraderamente perversa, violenta, degradante, y ha convertido a la gente no-blanca en animales y a las mujeres blancas en reproductoras de La Raza (blanca) y La Clase (burguesa). (Lugones, 2008, p. 93)

De esta manera Lugones completa la desnaturalización de aquellos factores constitutivos de la ficción del género que se mantendrian fuera del alcance de la problematización que hace Quijano del género en su análisis de la colonialidad de poder. Es en este sentido que "problematizar el dimorfismo biológico y considerar la relación entre el dimorfismo biológico y la construcción dicotómica de género es central para entender el alcance, la profundidad y las características del sistema de género colonial/moderno" (Lugones, 2008, p. 93). 
De igual manera, la problematización y desnaturalización de estas dimensiones de la colonialidad del género, en tanto eje constitutivo de la matriz colonial de poder, es parte fundamental de la crítica política y epistémica feminista que propicia el desprendimiento androcéntrico en la perspectiva descolonial.

Concluyendo su análisis con una frase que sintetiza en buena medida su crítica a la conceptualización del género en Quijano, afirma que "La raza no es ni más mítica ni más ficticia que el género -ambas son ficciones poderosas" (Lugones, 2008, p. 95).

\section{Consideraciones finales}

Con estas reflexiones buscamos contribuir a la profundización de la comprensión del lugar del género y la sexualidad en la matriz colonial de poder, con el fin de aportar al vuelco feminista dentro del vuelco descolonial, al desprendimiento androcéntrico que estire y desafie los límites del desprendimiento epistemológico propiciado por la perspectiva descolonial.

A partir de la revisión de los aportes teóricos de las intelectuales feministas estudiadas, podemos aproximarnos a una mejor comprensión "de la importancia y la magnitud del género en la desintegración de las relaciones comunales e igualitarias, del pensamiento ritual, de la autoridad y el proceso colectivo de toma de decisiones, de las economias" (Lugones, 2008, pp. 92-93).

Mignolo afirma que,

Cuando la teoría crítica se convierte en teoría crítica descolonial deviene pensamiento crítico de frontera y, al hacerlo, el vuelco epistémico descolonial [la descolonización del saber y del ser] marca los límites eurocéntricos de la teoría crítica tal como la conocemos hoy. (2010, p. 98)

Por mi parte, quisiera concluir este trabajo afirmando que, cuando la teoría crítica descolonial se convierte en teoría crítica descolonial y feminista, el vuelco epistémico feminista descolonial (la despatriarcalización/descolonización del saber y del ser), marca los límites androcéntricos de la teoría descolonial que conocemos hoy. 


\section{Referencias}

Allen, P. G. (1992). The Shared Hoop. Recoveting the feminine in American Indian Traditions. Boston: Beacon Press.

Dussel, E. (1977). Filosofía de la Liberación. México: Edicol.

Federici, S. (2011). Calibán y la bruja. Mujeres, cuerpo y acumulación originaria. Buenos Aires: Tinta Limón Ediciones.

Lugones, M. (2008, julio-diciembre). Colonialidad y Género. Tábula Rasa, (9) 73-101.

Mignolo, W. (2010). Desobediencia epistémica: retórica de la modernidad, lógica de la colonialidad, gramática de la descolonialidad. Buenos Aires: Ediciones del Signo.

Oyewúmi, O. (1997). The Invention of women. Making an African sense of western gender discourses. Minneapolis: University of Minnesota Press.

Parinetto, L. (1998). Streghe e Potere: Il Capitali e la persecuciones dei Diversi. Milan: Rusconi.

Pateman, C. (1988). The Sexual Contract, Stanford: Stanford University Press.

Quijano, A. (2000). Colonialidad del poder, eurocentrismo y América Latina. En Colonialidad del saber, eurocentrismo y ciencias sociales (pp. 201-246). Buenos Aires: CLACSO-UNESCO.

Silverblatt, I. (1987). Moon, Sun and Witches: Gender Ideologies and Class in Inca and Colonial Peru. Princeton: Princeton University Press.

Silverblatt, I. (1990). La Luna, el Sol y las Brujas: Género y Clase en los Andes Pre-Hispánicos y Coloniales. Cuzco: Centro de Estudios Bartolomé de las Casas.

\section{Cómo citar este artículo}

Fabbri, L. (2014). Desprendimiento androcéntrico. Pensar la matriz colonial de poder desde los aportes de Silvia Federici y María Lugones. Universitas Humanistica, 78, 89-107. http://dx.doi.org/10.11144/Javeriana.UH78.dapl 